\title{
Capítulo 5 - Uma bomba em verso, prosa e canção História, Arte e Tecnologia nas aulas de Física
}

\author{
Winston Gomes Schmiedecke \\ Paulo Alves Porto
}

\section{SciELO Books / SciELO Livros / SciELO Libros}

SCHMIEDECKE, W.G., and PORTO, P.A. Uma bomba em verso, prosa e canção: História, Arte e Tecnologia nas aulas de Física. In: MOURA, B. A., and FORATO, T. C. M., comps. Histórias das ciências, epistemologia, gênero e arte: ensaios para a formação de professores [online]. São Bernardo do Campo, SP: Editora UFABC, 2017, pp. 93-114. ISBN 978-85-68576-84-7. https://doi.org/10.7476/9788568576847.0006.

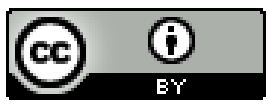

All the contents of this work, except where otherwise noted, is licensed under a Creative Commons Attribution 4.0 International license.

Todo o conteúdo deste trabalho, exceto quando houver ressalva, é publicado sob a licença Creative Commons Atribição 4.0.

Todo el contenido de esta obra, excepto donde se indique lo contrario, está bajo licencia de la licencia Creative Commons Reconocimento 4.0. 


\section{UMA BOMBA EM VERSO, PROSA E CANÇÃO: HISTÓRIA, ARTE E TECNOLOGIA NAS AULAS DE FÍSICA}

Winston Gomes Schmiedecke Paulo Alves Porto

\section{Introdução}

O êxito do Projeto Manhattan em produzir as primeiras bombas atômicas da história deve, em grande parte, ser atribuído ao trabalho de um grupo de cientistas que somente pôde ser reunido em torno de um objetivo comum em função do combate às forças do Eixo (Alemanha, Itália e Japão) pelos Aliados, na Segunda Grande Guerra Mundial. A imigração forçada para os EUA, de vários cientistas europeus de renome, tais como Enrico Fermi (1901-1954), Leó Szilárd (1898- 1964), Niels Bohr (18851962) e Edward Teller (1908-2003), mostrou-se determinante para os fins do Projeto Manhattan. Foi o trabalho conjunto dessas personalidades com cientistas estadunidenses, além do esforço de milhares de trabalhadores, que possibilitou o enorme desenvolvimento científico e tecnológico observado, alcançado em um espaço de tempo incomum na história da humanidade. 
A conjunção de ideias e esforços desses cientistas não ocorreu de forma espontânea, ou seja, não foi determinada pelo alinhamento de interesses oriundos das pesquisas em ciências desenvolvidas de forma individual e anterior às mudanças provocadas pela guerra. Não é possível fazer uma projeção do que esses cientistas poderiam ter oferecido à sociedade se, em vez de se dedicarem ao Projeto Manhattan, houvessem prosseguido em seus destinos e pesquisas anteriores. Contudo, é improvável que lograssem êxito - ou mesmo que tivessem interesse - em produzir artefatos nucleares do porte das bombas lançadas sobre o Japão, em 1945.

Esse é um exemplo de influência, advinda do meio social, sobre os rumos tomados pela ciência e seus produtos, evidenciando que os cientistas nem sempre guiam suas pesquisas em uma direção escolhida ou pré-determinada por eles próprios. Teller, por exemplo, era conhecido no final da década de 1930 por seus trabalhos em química, utilizando a Teoria de Grupos para explicar fenômenos eletrônicos, até então sem qualquer relação com o fenômeno da fissão nuclear, que já era estudado pelo grupo de Fermi. Todavia, no contexto aqui abordado, a presença de Teller está associada a fatos independentes de suas contribuições para a química.

Muitos são os setores da sociedade civil que estão atentos e sensíveis às consequências geradas pelos resultados da ciência. Como resultado, vozes dissonantes podem expressar suas críticas por meio de variadas formas de manifestações culturais, como literatura, cinema, música, teatro etc. Nesse sentido, oferecer aos estudantes a possibilidade de apreender e integrar essas manifestações com o conhecimento científico seria uma forma de enriquecer com significados e sentidos o aprendizado dos conteúdos de ciências no ensino médio. No presente trabalho, são 
abordadas manifestações culturais relacionadas a um tema de grande impacto sobre a sociedade: a bomba atômica.

Considerando a importância de se respeitar as características e contingências de cada contexto em que os docentes se encontram inseridos profissionalmente, optamos aqui por oferecer um conjunto de sugestões alinhadas com os conteúdos curriculares de Física para o ensino médio, apresentando materiais e atividades didáticas voltadas ao desenvolvimento dos temas e evidenciando os recursos didáticos envolvidos.

O conteúdo científico mais claramente associado ao episódio descrito neste trabalho é a física nuclear, ramo da ciência que possui inúmeras aplicações no âmbito das diversas frentes de pesquisa exploradas a partir de seus fundamentos. Uma tentativa de se contar uma história da física nuclear que abrangesse todas essas investigações e, também, as tecnologias delas decorrentes, seria uma tarefa hercúlea e, tratando-se dos propósitos didáticos de aplicação desse material, fadada a oferecer informações pontuais e desarticuladas, que pouco valor e sentido teriam para os estudantes. No contexto escolar da física no ensino médio, a qualidade das articulações realizadas é mais importante que a quantidade de informações fornecidas, sendo fundamental que os estudantes consigam associar as informações àquilo que está presente em seu cotidiano.

Um documento recente, que reforça a relevância dos assuntos abordados por essa atividade, é a Base Nacional Comum Curricular (BNCC). Sua versão preliminar, destinada a passar por rodadas de negociação junto aos diversos setores da sociedade, declarava ser fundamental que as aulas de física do ensino médio, no trabalho com a unidade de conhecimento Matéria e radiação em sistemas e processos naturais e tecnológicos, abrissem espaço para o respectivo histórico associado. Textualmente, 
a BNCC sugeria ser necessário promover junto aos alunos a análise dos "[...] vários eventos envolvendo o uso da energia nuclear, desde a explosão de bombas atômicas, o vazamento de usinas de geração de energia até descarte de material radioativo" (BRASIL, 2015, p. 218).

\section{Aportes teóricos e metodológicos}

As atividades didáticas sugeridas neste trabalho visam promover o diálogo entre duas áreas do conhecimento: a História da Ciência e o Ensino de Ciências. Assim sendo, alguns referenciais teóricos e metodológicos foram utilizados para dar sustentação a essa aproximação.

No que se refere à utilização de critérios historiográficos, a elaboração do material buscou contemplar a contemporânea historiografia da ciência, ao priorizar: a análise pontual de um caso histórico, privilegiando a investigação de um acontecimento específico; a apresentação das ideias atreladas ao contexto sócio-histórico-cultural em que foram propostas; e o realce à influência de fatores externos (de natureza psicológica, política e social, por exemplo) na prática científica (BALDINATO; PORTO, 2008; PORTO, 2010).

A escolha pelo emprego de recursos audiovisuais busca trabalhar conhecimentos específicos de maneira mais dinâmica e plural nas aulas de ciências, recorrendo a uma linguagem mais próxima do cotidiano dos alunos em relação àquela que caracteriza os livros didáticos ou, ainda, os textos acadêmicos. Essa tendência tem sido discutida e explorada pela literatura especializada nas últimas décadas (CARVALHO, 1993; MORÁN, 1995; ARROIO; GIORDAN, 2006; REZENDE, 2008). 
Considerando a história da ciência como mais um entre os diversos recursos didático-pedagógicos atualmente disponíveis para o professor de ciências desenvolver os conteúdos de sua disciplina, a associação com outros recursos pode tornar seus resultados mais eficazes. Recente levantamento realizado junto a licenciandos em Física de duas instituições de ensino superior da cidade de São Paulo mostrou que a história e a filosofia da ciência (HFC) ainda enfrentam resistências e obstáculos para sua aproximação com a sala de aula:

Constatar que a HFC nem de longe se configura em uma estratégia didático-pedagógica ocupando espaço privilegiado dentre a preferência dos professores em formação reforça a necessidade de se propor outras formas de utilizá-la (em particular, a História da Ciência) nas aulas de Física da Escola Básica. Por exemplo, pode-se associá-la aos demais recursos disponíveis, com valores didáticos mais bem estabelecidos junto ao imaginário dos licenciandos, caso da Experimentação, da Abordagem CTS(A) e da Resolução de Problemas. (SCHMIEDECKE; TADEU NETO, 2015, p. 8)

É preciso, portanto, considerar que os futuros professores tenham a adequada fundamentação para lidar com essas temáticas e estratégias (SCHMIEDECKE; PORTO, 2014). Tendo em vista o cenário aqui delineado, propomos, neste trabalho, duas atividades, pautadas pela possibilidade de composição harmoniosa entre os diferentes aspectos que caracterizam os recursos didático-pedagógicos mobilizados. ${ }^{1}$ Além disso, sendo coerente com o tom de diálogo que procuramos manter com os docentes ao apresentar o material, delegamos aos professores a escolha,

\footnotetext{
1 As duas atividades aqui apresentadas foram extraídas de um conjunto original de onze atividades, propostas por Schmiedecke (2016).
} 
a articulação e o encadeamento das estratégias e atividades aqui sugeridas, a serem feitas em sintonia com seus propósitos didáticos e, principalmente, com a dinâmica de cada cotidiano profissional.

\section{Atividade 1: Documentários Projeto Manhattan e Luz Branca, Chuva Negra}

Com a devida antecedência, sugere-se ao docente solicitar que os alunos assistam ao documentário em vídeo "Projeto Manhatan", pertencente à série "Maravilhas Modernas", produzido em 2002 pelo canal de TV estadunidense The History Channel $^{2}$, por ser muito extenso para exibição em uma aula. Dentre outras informações, o vídeo apresenta as justificativas dos construtores das bombas atômicas para lançá-las sobre o Japão no ano de 1945.

$\mathrm{O}$ docente pode escolher previamente um grupo de 3 a 4 alunos, o qual ficaria encarregado de apresentar à classe uma breve exposição das principais informações presentes no vídeo, como uma síntese das ideias prévias para dar início às discussões. Após a apresentação feita pelo grupo, ainda na mesma aula, o docente apresenta aos alunos as seguintes questões:

I. Por que as forças armadas estadunidenses lançaram as duas bombas atômicas sobre as cidades japonesas de Hiroshima e Nagasaki, mesmo após o poderio militar do Japão já ter sido praticamente dizimado?

\footnotetext{
${ }^{2}$ As primeiras quatro partes do documentário, dubladas em português, estão disponíveis no site YouTube (2011a, 2011b, 2011c, 2011d) - faltando apenas a quinta e última parte, com cerca de sete minutos de duração. O vídeo original, em inglês, está disponível na íntegra, no mesmo site (YouTube, 2002).
} 
II. Referindo-se aos milhares de pessoas contratadas para trabalharem nos centros de produção do material físsil utilizado nas bombas do Projeto Manhattan, o historiador e jornalista Richard Rhodes faz o seguinte comentário: "Era duro conseguir operários durante a guerra. A solução dele [General Leslie Groves, dirigente máximo do projeto] foi pôr anúncios assim: 'não podemos dizer o que vocês farão, mas haverá bife na mesa todas as noites'”. Por outro lado, boa parte dos cientistas que trabalharam nesse empreendimento era composta por imigrantes europeus refugiados da guerra, que de maneira consciente se ofereceram ou aceitaram esse trabalho sem muito relutar. Em sua opinião, há alguma contradição nas posturas desses dois grupos? Por quê?

III. Sobre a corrida das duas superpotências do Pós-Guerra (EUA e URSS) voltada à constituição de arsenais nucleares, o cientista húngaro Edward Teller (1908-2003), naturalizado estadunidense, declarou: "O progresso não pode ser detido. Dizem-nos [i.e., aos cientistas] para deter o progresso. Temo que o progresso venha a ocorrer num país menos dedicado à paz do que nós [EUA]". Procure relacionar essa declaração de Teller com as restrições impostas pelas potências nucleares aos demais países do mundo, por meio do Acordo de Não Proliferação de Armas Nucleares.

IV. Ainda que não tenha colaborado diretamente com a execução das ações do Projeto Manhattan, Albert Einstein (1879-1955) foi responsável pela elaboração de uma teoria que forneceu importantes subsídios teóricos utilizados para a fabricação das bombas atômicas. Qual é o mais conhecido enunciado matemático que integra essa 
teoria, e de que forma ele ajuda a explicar o extraordinário poder destrutivo da explosão de bombas atômicas?

Com esse conjunto de questões, é possível desenvolver com os alunos discussões destinadas, respectivamente, a:

I. reforçar a importância do contexto sociopolítico nas pesquisas realizadas em ciência, bem como das decisões a respeito dos consequentes rumos tomados por suas aplicações tecnológicas;

II. situar os cientistas no mesmo plano das demais pessoas que constituem a sociedade civil, por diversas vezes forçadas a tomarem decisões que transcendem a compreensão dos limites éticos tradicionais; ou seja, em determinados momentos da vida, tanto os chamados "cidadãos comuns", como os cientistas, se submetem ao desempenho de trabalhos destinados à obtenção de resultados com os quais esses sujeitos não concordariam segundo suas crenças e valores pessoais;

III. evidenciar que a prática do veto realizada por parte das nações ditas "desenvolvidas" - geralmente acompanhado por boicotes e imposição de sanções à possibilidade de as tecnologias de ponta serem compartilhadas com as nações "em desenvolvimento" - é um dos fatores que concorrem para a manutenção do atraso científico destas últimas, e um dos responsáveis pelo aumento da desigualdade socioeconômica entre os diversos países do mundo;

IV. dar sentido para aquela que, talvez, seja a equação mais conhecida da física, apresentando aos alunos a equivalência entre massa e energia ("balanço energético") presente no processo de fissão nuclear, de modo que eles 
entendam de onde vem a energia liberada na explosão de uma bomba atômica, bem como o processo de aproveitamento dessa energia nas usinas termonucleares.

Terminado o primeiro bloco de aulas dessa atividade, passa-se ao trabalho com o documentário "Luz Branca, Chuva Negra: a destruição de Hiroshima e Nagasaki", produzido em 2007 pela também estadunidense $H B O^{3}$. Se o vídeo anterior expõe a opinião daqueles que venceram a corrida para a construção da bomba atômica (e a guerra), este outro documentário - dirigido pelo nipo-americano Steven Okazaki -, oferece a outra face da moeda, trazendo o relato de mais de uma dúzia de sobreviventes dos bombardeios nucleares, além de consequências derivadas do Projeto Manhattan não exploradas no documentário do The History Channel.

Trata-se de um vídeo longo, com quase 1h30min de duração. Portanto, é conveniente disponibilizar de antemão aos alunos as questões a serem discutidas em sala de aula, como forma de nortear sua atenção em relação a determinados fatos, presentes no vídeo, já selecionados para serem aprofundados. Nesse caso, o grupo escolhido para apresentar a síntese do documentário já ficaria responsável por iniciar, em sala de aula, a discussão das seguintes questões:

I. Os EUA são reconhecidos pela facilidade com que transformam conhecimentos científicos adquiridos em contextos de guerra em importantes aplicações tecnológicas para o uso civil. O vídeo destaca a proibição prevista na constituição japonesa, redigida com influência das forças de ocupação estadunidenses, no tocante à existência de forças armadas e à produção de armas no

3 Disponível em: <http://www.youtube.com/watch?v=--p1ZVMOUjw>. 
Japão ressurgido do Pós-Guerra. Todavia, o Japão é uma nação celebrada mundialmente pelo alto nível de desenvolvimento tecnológico de suas diversas empresas. O que poderia explicar esse aparente paradoxo?

II. O copiloto do avião que lançou a bomba sobre Hiroshima, Capitão Robert Lewis, participa do programa de TV destinado a homenagear Kiyoshi Tanimoto, religioso japonês que levantava fundos para as vítimas das bombas atômicas. Isso ocorreu em 1955, dez anos após o final da guerra. No programa, Lewis aparece fazendo doações para Tanimoto, segundo suas próprias palavras, "em nome da equipe que participou daquela missão, de minha empresa e de minha adorável família". Conforme destacado pelo apresentador do programa, a mencionada empresa era a Henry Heide Ltd., atuante no ramo de balas e gomas de mascar. A princípio, esse fato soa estranho, pois, como herói de guerra, seria razoável imaginar que Lewis tivesse continuado sua carreira profissional como militar. Faça uma breve pesquisa visando explicar a razão do Capitão Lewis e vários outros militares estadunidenses atuantes na Segunda Grande Guerra Mundial terem ido trabalhar na iniciativa privada ao final da guerra, realidade que, na época, gerou consequências diretas no modo de participação das mulheres no mercado de trabalho dos EUA.

III. É possível estabelecer relações entre os dois documentários. Por exemplo, ao término da Segunda Grande Guerra, a possibilidade de aniquilamento da população mundial, concretizada pela constatação do poder das bombas atômicas, trouxe a sensação de absoluta impotência e desconfiança às pessoas, quaisquer que fossem 
as sociedades em que viviam. Apesar disso, durante a Guerra Fria, os governos dos EUA e do Japão conduziram suas ações de maneiras muito diferentes no âmbito dos usos da energia nuclear. Enquanto os EUA seguiram investindo pesadamente no desenvolvimento de armas nucleares - em quantidade e variedade -, o Japão limitou-se a investir recursos materiais e humanos no sentido de utilizar a tecnologia nuclear para a geração de energia elétrica e, também, de descobrir novas possibilidades de aplicação da energia nuclear na resolução de problemas cotidianos da sociedade. Como resultado, o Japão conta atualmente com uma série de indústrias que dominam e comercializam a tecnologia nuclear em nível mundial. A empresa nipônica Toshiba, por exemplo, desenvolveu-se a ponto de comprar, em 2006, a estadunidense Westinghouse - responsável, nos anos 1970, pela construção da usina nuclear de Angra I, no Brasil. A partir do levantamento de informações junto a fontes fidedignas, faça uma comparação entre os exemplos do Japão e do Brasil na exploração e nos usos da energia nuclear. Não se esqueça de citar suas fontes.

Dentre outras possibilidades, essas questões permitem ao docente discutir importantes aspectos que ajudam a desmitificar a prática científica, bem como explorar fatos cotidianos e aplicações tecnológicas cuja origem é desconhecida pela maioria dos alunos. Seguem-se comentários sobre cada questão, visando lançar luz sobre alguns aspectos passíveis de serem explorados:

I. Não existe um único, inequívoco e universal método científico capaz de gerar resultados invariavelmente equivalentes em contextos sociais distintos. Ou seja, a 
"fórmula" de sucesso para as relações entre ciência, tecnologia e sociedade que funciona para um determinado país pode não servir para outros, fato refletido nas políticas de Estado voltadas ao investimento em educação, pesquisa e desenvolvimento social. Este é o caso de EUA e Japão, nações constituídas com base em influências geográficas e culturais muito diferentes;

II. Cerca de 16 milhões de pessoas serviram às Forças Armadas dos EUA no contexto da Segunda Grande Guerra Mundial. Em sua absoluta maioria, esse contingente era formado por pessoas do sexo masculino. Como forma de manter a economia em funcionamento, as empresas passaram a contratar um número expressivo de mulheres para ocupar os postos vagos devido à guerra. Contudo, terminada a guerra, os homens retornaram aos EUA, cujo governo não tinha mais motivo para manter o mesmo contingente de militares e demais profissionais em sua folha de pagamento. Como forma de reinserir tais sujeitos no mercado de trabalho, as mulheres foram "convidadas" a procurar outras maneiras para se manterem economicamente ativas - e, de preferência, sem abandonarem seus lares. Nesse momento, ganharam espaço as diversas empresas que baseavam a venda direta de seus produtos em reuniões promovidas por muIheres em suas próprias residências, dentre as quais um exemplo bastante conhecido é o da fabricante de vasiIhas plásticas Tupperware. Sob um olhar mais abrangente, trata-se de mais um reflexo das complexas relações envolvendo ciência, tecnologia e sociedade, pois parte da demanda pelo aumento de empregos, diretos ou indiretos, surgida durante a guerra, ocorreu em função da instalação do Projeto Manhattan; e 
III. A Westinghouse foi a empresa que vendeu ao Brasil o projeto da usina termonuclear Angra I, e a construiu nos anos 1970, pouco mais de 25 anos após o final da Segunda Grande Guerra Mundial. Passadas três décadas, e sendo unicamente autorizado a trabalhar com pesquisas destinadas aos usos pacíficos da energia nuclear, o Japão atingiu um nível de desenvolvimento nessa área que permitiu às suas empresas a aquisição de tradicionais conglomerados estadunidenses. O Brasil parece ter trilhado a contramão desse processo, visto que segue tentando superar uma série de dificuldades tecnocientíficas para concluir a usina Angra III.

Ao utilizar os dois documentários destacados, o docente permite aos estudantes confrontarem os objetivos e interesses dos elaboradores e veiculadores desses materiais e, também, perceberem suas possibilidades e limitações enquanto recursos didáticos. Existem diferenças significativas entre trabalhos de reconhecido valor historiográfico e aqueles destinados essencialmente à divulgação científica. Sobre essa realidade, Rezende (2008, p. 2-3) foi particularmente preciso, ao afirmar que,

[...] por visarem frequentemente à divulgação, os filmes científicos tendem a "tomar um partido", ou seja, a defender uma determinada teoria ou visão em detrimento de outras. Neste caso, eles precisam ser analisados tanto como elementos que se integram às disputas pelo reconhecimento público da ciência, quanto como obras que resultam de determinadas configurações das intenções de seus autores e de seus contextos de produção.

Nessa atividade, os estudantes têm a oportunidade de refletir sobre as posições dos "vencedores", dos "vencidos" 
e dos países "periféricos" em relação à ciência e a tecnologia. Questões como a concepção de ciência como conhecimento universalmente compartilhado, e a suposta neutralidade da ciência, podem ser discutidas nesse contexto.

\section{Atividade 2: Poesia (Rosa de Hiroshima) e Música (Enola Gay)}

Os resultados das principais investigações feitas em ciência afetam a sociedade como um todo, sendo retratados a partir dos mais diversos ângulos e formas. A Literatura e as Artes, por exemplo, sempre estiveram atentas a essa relação. Nesse sentido, a história é rica em exemplos de escritores e artistas que expressaram os sentimentos mais comuns e contraditórios da sociedade civil (preocupação, confiança, admiração, contrariedade, esperança, desilusão, euforia, consternação) envolvendo as realizações do conjunto de ações e descobertas científicas com os quais se depararam ao longo de suas existências.

Com o objetivo de realizar junto aos alunos uma leitura crítica e atenta de exemplos associados à relação estabelecida historicamente entre a ciência e outras manifestações culturais, a presente atividade utiliza uma conhecida poesia do brasileiro Vinicius de Moraes (1913-1980) e, também, uma canção da banda britânica OMD (Orchestral Manoeuvers in the Dark).

Compostas com uma diferença de 26 anos entre si, em momentos distintos da Guerra Fria, Rosa de Hiroshima ${ }^{4}$ (1954)

\footnotetext{
4 Ou Rosa de Hiroxima, na grafia originalmente utilizada por Vinicius de Moraes e atualmente em desuso no Brasil. O poema se tornou bastante conhecido após ser musicado por Gerson Conrad e gravado pela banda Secos e Molhados, em disco de 1973. Posteriormente, a canção foi regravada pelo ex-vocalista
} 
e Enola Gay (1980) expressam em suas letras a indignação de duas sociedades separadas no tempo e no espaço, mas unidas pelo sentimento comum de reprovação às centenas de milhares de mortes provocadas pelo lançamento das bombas atômicas em 1945 e, também, pela sensação de impotência diante do alcance dos produtos obtidos a partir da tecnologia nuclear.

As guerras que se sucederam em países da Ásia (Indochina, Coreia, Vietnã) e outros conflitos internacionais (construção do muro de Berlim, posicionamento de mísseis soviéticos em Cuba, deflagração da "Primavera de Praga" etc.) representaram o risco premente de encaminhamento para uma "solução" nuclear. Tal realidade não poderia passar incólume ao olhar de personalidades ligadas aos diversos setores da sociedade civil, dando origem a críticas e manifestações de caráter pacifista.

Apresentamos, no Quadro 1, o poema Rosa de Hiroshima e a letra de Enola Gay, acompanhada de sua tradução para o português. Há diversas maneiras de se explorar esse material, em sintonia com as intenções e a sensibilidade do docente em relação às possibilidades de interlocução a serem promovidas em cada particular contexto didático ${ }^{5}$.

No caso de se propor uma leitura crítica aos alunos, esta poderia se centrar na identificação das referências feitas pelos autores de cada letra (Rosa de Hiroshima e Enola Gay) em relação às bombas lançadas sobre o Japão, no final da Segunda Grande Guerra.

dos Secos e Molhados, Ney Matogrosso, sendo uma das mais conhecidas do repertório de sua bem-sucedida carreira solo.

5 Outro texto de autor brasileiro que poderia ser utilizado em atividade semeIhante é o poema A Bomba, de Carlos Drummond de Andrade (1902-1987). Entretanto, por ser muito extenso e fazer uso de um vocabulário mais complexo, que requer uma discussão mais elaborada, evitamos abordá-lo no contexto deste trabalho. 
Quadro 1 - Letras de duas manifestações artísticas que se referem à bomba atômica lançada sobre Hiroshima

\begin{tabular}{|c|c|c|}
\hline \multirow{2}{*}{$\begin{array}{l}\text { Rosa de Hiroshima } \\
\text { (Brasil - 1954) }\end{array}$} & \multicolumn{2}{|l|}{$\begin{array}{l}\text { Enola Gay } \\
\text { (Inglaterra, 1980) }\end{array}$} \\
\hline & Original (Inglês) & Tradução (Português) \\
\hline $\begin{array}{l}\text { Pensem nas crianças } \\
\text { Mudas telepáticas } \\
\text { Pensem nas meninas } \\
\text { Cegas inexatas } \\
\text { Pensem nas mulheres } \\
\text { Rotas alteradas } \\
\text { Pensem nas feridas } \\
\text { Como rosas cálidas } \\
\text { Mas oh não se esqueçam } \\
\text { Da rosa da rosa } \\
\text { Da rosa de Hiroshima } \\
\text { A rosa hereditária } \\
\text { A rosa radioativa } \\
\text { Estúpida e inválida } \\
\text { A rosa com cirrose } \\
\text { A antirrosa atômica } \\
\text { Sem cor sem perfume } \\
\text { Sem rosa sem nada. }\end{array}$ & $\begin{array}{l}\text { Enola Gay, } \\
\text { you should have stayed at home } \\
\text { yesterday } \\
\text { Words can't describe } \\
\text { the feeling and the way you lied } \\
\text { These games you play } \\
\text { they're going to end in more than } \\
\text { tears someday } \\
\text { Enola Gay, } \\
\text { it shouldn't ever have to end this } \\
\text { way } \\
\text { It's eight fifteen } \\
\text { and that's the time that it's } \\
\text { always been } \\
\text { We got your message on the radio } \\
\text { Conditions normal and you're } \\
\text { coming home } \\
\text { Enola Gay, } \\
\text { is mother proud of little boy } \\
\text { today? } \\
\text { This kiss you give, } \\
\text { it's never ever going to fade away } \\
\text { Enola Gay, } \\
\text { it shouldn't ever have to end this } \\
\text { way } \\
\text { Enola Gay, } \\
\text { it shouldn't fade in our dreams } \\
\text { away } \\
\text { It's eight fifteen } \\
\text { and that's the time that it's } \\
\text { always been } \\
\text { We got your message on the radio } \\
\text { Conditions normal and you're } \\
\text { coming home } \\
\text { Enola Gay, } \\
\text { is mother proud of little boy } \\
\text { today? } \\
\text { This kiss you give, } \\
\text { it's never ever going to fade away }\end{array}$ & $\begin{array}{l}\text { Enola Gay, } \\
\text { você deveria ter ficado em } \\
\text { casa ontem } \\
\text { Palavras não podem descrever } \\
\text { o sentimento e o jeito com que } \\
\text { você mentiu } \\
\text { Qualquer dia, seus jogos } \\
\text { serão mais que sofrimento } \\
\text { Enola Gay, isso nunca deveria } \\
\text { ter terminado desse jeito } \\
\text { São } 8 \text { h15 e essa é a hora que } \\
\text { sempre foi } \\
\text { Recebemos sua mensagem } \\
\text { pelo rádio } \\
\text { As condições estão normais e } \\
\text { você está voltando para casa } \\
\text { Enola Gay, } \\
\text { a mãe hoje está orgulhosa de } \\
\text { seu garotinho? } \\
\text { O beijo que você dá jamais irá } \\
\text { desaparecer } \\
\text { Enola Gay, isso nunca deveria } \\
\text { ter terminado desse jeito } \\
\text { Enola Gay, isso não deveria } \\
\text { ter desaparecido dos nossos } \\
\text { sonhos } \\
\text { São } 8 \text { h15 e essa é a hora que } \\
\text { sempre foi } \\
\text { Recebemos sua mensagem } \\
\text { pelo rádio } \\
\text { As condições estão normais e } \\
\text { você está voltando para casa } \\
\text { Enola Gay, } \\
\text { a mãe hoje está orgulhosa de } \\
\text { seu garotinho? } \\
\text { O beijo que você dá jamais irá } \\
\text { desaparecer }\end{array}$ \\
\hline
\end{tabular}

Fonte: Elaborado pelos autores.

${ }^{6}$ Disponível em: http://www.viniciusdemoraes.com.br/pt-br/poesia/poesias-avulsas/ rosa-de-hiroxima. Acesso em: 03 out. 2016.

7 Letra extraída da versão interpretada no filme Urgh! A Music War (1981). Disponível no site oficial da banda: <http://www.omd.uk.com/video/enola_gay_live>.

8 Tradução nossa. 
O Quadro 2, a seguir, apresenta alguns termos e expressões presentes nas letras destacadas, que constituem uma visão do mencionado episódio histórico expressa por meio de manifestações culturais "não científicas":

Quadro 2 - Termos e referências à bomba atômica lançada sobre o Japão, em 6 de agosto de 1945, presentes no poema Rosa de Hiroshima e na letra de Enola Gay

\begin{tabular}{|c|c|c|}
\hline Letra & Termos / Expressões & Referências \\
\hline $\begin{array}{l}\text { Rosa de } \\
\text { Hiroshima }\end{array}$ & $\begin{array}{l}\text { Crianças mudas } \\
\text { Meninas cegas } \\
\text { Rotas alteradas } \\
\text { Rosa sem perfume } \\
\text { Rosa radioativa }\end{array}$ & $\begin{array}{l}\text { Doenças causadas pela radiação } \\
\text { Destino e realidades sociais } \\
\text { mudadas pela necessidade de } \\
\text { reconstrução das cidades } \\
\text { Formato da nuvem gerada pela } \\
\text { explosão } \\
\text { Características e efeitos da radiação } \\
\text { expressos por figuras de linguagem }\end{array}$ \\
\hline Enola Gay & $\begin{array}{l}8 \mathrm{~h} 15 \\
\text { Little boy } \\
\text { Enola Gay } \\
\text { Mãe orgulhosa }\end{array}$ & $\begin{array}{l}\text { Horário do lançamento da bomba } \\
\text { sobre Hiroshima } \\
\text { Nome com o qual os militares } \\
\text { estadunidenses batizaram a bomba } \\
\text { de urânio } \\
\text { Nome dado ao avião B-29 que } \\
\text { lançou a bomba de urânio sobre } \\
\text { Hiroshima } \\
\text { O avião tem o mesmo nome que a } \\
\text { mãe do piloto do B-29 } \\
\text { Linguagem figurativa em alusão aos } \\
\text { males de longa duração causados } \\
\text { pela bomba atômica }\end{array}$ \\
\hline
\end{tabular}

Fonte: Elaborado pelos autores.

Ao conduzir a atividade nesses moldes, o docente permite aos seus alunos o contato e a compreensão de termos e fatos relacionados a um importante episódio histórico a partir de outras perspectivas, diferentes da tradicional apresentação 
de informações técnicas, como é comum em livros didáticos e paradidáticos. Ou seja, muda-se o foco: em vez de a ciência contar sua própria história, é a sociedade, por meio de seus diversos interlocutores, que apresenta sua versão acerca do impacto da ciência em seu cotidiano e em sua dinâmica de existência e sobrevivência.

O Quadro 3 apresenta, a seguir, os conteúdos programáticos de física para o ensino médio que podem ser contemplados no contexto dessas atividades, as ferramentas e atividades didáticas sugeridas para o desenvolvimento dos temas e, também, algumas estratégias didáticas mobilizadas ${ }^{9}$.

Quadro 3 - Conteúdos programáticos de física que podem ser trabalhados, a partir das respectivas ferramentas e atividades didáticas sugeridas, e estratégias didáticas mobilizadas nas atividades

\begin{tabular}{|c|c|c|}
\hline $\begin{array}{l}\text { Conteúdos } \\
\text { Programáticos }\end{array}$ & $\begin{array}{l}\text { Ferramentas e Atividades } \\
\text { Didáticas Sugeridas }\end{array}$ & $\begin{array}{l}\text { Estratégias } \\
\text { Didáticas }\end{array}$ \\
\hline \multirow[t]{2}{*}{$\begin{array}{l}\text { Fontes de Energia } \\
\text { Transformações } \\
\text { Energéticas }\end{array}$} & $\begin{array}{l}\text { 1) Documentários Projeto Manhattan } \\
\text { e Luz Branca, Chuva Negra: discussões } \\
\text { reafirmando a possibilidade de } \\
\text { existirem diferentes leituras a respeito } \\
\text { de um mesmo episódio histórico, } \\
\text { baseadas em narrativas guiadas } \\
\text { por pontos de vista, interesses e } \\
\text { influências culturais distintas }\end{array}$ & $\begin{aligned} \checkmark & \text { Abordagem } \\
& \text { Ciência, Tecnologia } \\
& \text { e Sociedade (CTS) } \\
\checkmark & \text { Recursos } \\
& \text { audiovisuais } \\
\checkmark & \text { História e Filosofia } \\
& \text { da Ciência (HFC) }\end{aligned}$ \\
\hline & $\begin{array}{l}\text { 2) Poesia (Rosa de Hiroshima) e } \\
\text { Música (Enola Gay): leitura crítica das } \\
\text { letras de duas formas de se expressar, } \\
\text { por meio da literatura e da arte, a } \\
\text { contrariedade, a consternação e a } \\
\text { preocupação com os resultados da } \\
\text { Ciência }\end{array}$ & $\begin{array}{l}\checkmark \text { Abordagem } \\
\text { Ciência, Tecnologia } \\
\text { e Sociedade (CTS) } \\
\checkmark \text { Interface Arte e } \\
\text { Ciência } \\
\checkmark \text { História e Filosofia } \\
\text { da Ciência (HFC) }\end{array}$ \\
\hline
\end{tabular}

Fonte: Elaborado pelos autores.

9 Para a identificação dos conteúdos programáticos, utilizamos como referências: 1) As Orientações Complementares aos Parâmetros Curriculares Nacionais (PCN+: Ensino Médio) (BRASIL, 2002); e 2) Os conteúdos programáticos discriminados nos sumários de algumas coleções aprovadas na mais recente edição do Guia do PNLD - 2015 (BRASIL, 2014). 


\section{Considerações finais}

Sob o olhar da história da ciência, o professor de ciências do ensino médio tem a prerrogativa de propor e sustentar, em situações didáticas, discussões que transcendam os limites de um aprendizado acrítico de conteúdos científicos meramente fundamentados na memorização. Encarada no contexto do ensino de ciências como uma estratégia didático-pedagógica, a história da ciência apresenta-se como provedora de um grande manancial de episódios a serem explorados pelos docentes, desde que sejam observados e respeitados os contemporâneos critérios historiográficos coerentes com seus objetivos educacionais.

Outros relevantes recursos podem ser mobilizados para viabilizar o desenvolvimento da abordagem histórica, buscando oferecer mais sentido e eficácia para as ações adotadas. Este trabalho apresenta a possibilidade de discussão de temas relacionados a um importante conteúdo da física moderna e contemporânea, por meio de recursos audiovisuais e de composições artísticas (poesia e música), devidamente integrados à apresentação de um episódio histórico abordado a partir de um viés historiográfico atual.

Ao explorar fatos históricos utilizando recursos que vão além do texto escrito, o professor pode caracterizar o contexto sociocultural relacionado à exploração de determinados fenômenos físicos sem se limitar a argumentos exclusivamente teórico-experimentais. Assim, abre-se espaço - parafraseando as recomendações presentes em diversos documentos oficiais que orientam o ensino no Brasil - para a efetiva promoção de uma educação científica verdadeiramente crítica, ativa e transformadora. 


\section{Referências}

ARROIO, Agnaldo; GIORDAN, Marcelo. O Vídeo Educativo: Aspectos da Organização do Ensino. Química Nova na Escola, n. 24, p. 8-11, 2006.

BALDINATO, José Otávio; PORTO, Paulo Alves. Variações da história da ciência no ensino de ciências. In: ENCONTRO NACIONAL DE PESQUISA EM EDUCAÇÃO EM CIÊNCIAS - ENPEC, 6., 2008, Belo Horizonte. Anais eletrênicos... Belo Horizonte: ABRAPEC, 2008. Disponível em: <http://www.nutes.ufrj.br/ abrapec/vienpec/autores0.html>. Acesso em: 5 jul. 2016.

BRASIL. PCN+ Ensino Médio: orientações educacionais complementares aos Parâmetros Curriculares Nacionais Ciências da Natureza, Matemática e suas Tecnologias. Brasília: MEC/SEB, 2002. Disponível em: <http://portal.mec.gov.br/seb/ arquivos/pdf/CienciasNatureza.pdf>. Acesso em: 11 jan. 2016.

BRASIL. Guia de livros didáticos: PNLD 2015 - Física. Brasília: MEC/SEB, 2014. Disponível em: <http://www.fnde.gov.br/ programas/livro-didatico/guias-do-pnld/item/5940-guiapnld-2015>. Acesso em: 11 jan. 2016.

BRASIL. Base Nacional Comum Curricular. Brasília: MEC/SEB, 2015.

CARVALHO, Ana Amélia Amorim Soares de. Utilização e exploração de documentos audiovisuais. Revista Portuguesa de Educação, v. 6, n. 3, p. 113-121, 1993.

LUZ BRANCA/Chuva Negra: A Destruição de Hiroshima e Nagazaki. 2011. 1 post (1h 25 min 37 s). Postado em: 20 dez. 
2011. Disponível em: <https://www.youtube.com/watch?v=-p1ZVMOUjw>. Acesso em: 22 maio 2012.

MORÁN, José Manuel. O vídeo na Sala de Aula. Comunicação \& Educação, v. 1, n. 2, p. 27-35, 1995. Disponível em: <http:// www.revistas.usp.br/comueduc/article/view/36131>. Acesso em: 11 jan. 2016.

ORCHESTRAL MANOEUVERS IN THE DARK. OMC Live at the Museum of Liverpool Trailler. 1 post. (1 min 37 s). Postado em: 2 jun. de 2015. Disponível em: <http://www.omd.uk.com/video/ enola_gay_live $>$. Acesso em: 17 jan. 2016.

PORTO, Paulo Alves. História e Filosofia da Ciência no Ensino de Química: em busca dos objetivos educacionais da atualidade. In: SANTOS, Wildson Luiz Pereira dos; MALDANER, Otavio Aloisio (Org.). Ensino de Química em Foco. ljuí: Editora Unijuí, 2010. p. 159-180.

REZENDE, Luiz Augusto. História das Ciências no ensino de Ciências: contribuições dos recursos audiovisuais. Ciência em Tela, v. 1, n. 2, p. 1-6, 2008.

SCHMIEDECKE, Winston Gomes. A história da ciência nacional na formação e na prática de professores de física. 2016. Tese (Doutorado em Ensino de Ciências) - Programa de Pós-Graduação Interunidades em Ensino de Ciências, Universidade de São Paulo, São Paulo, 2016.

.; PORTO, Paulo Alves. Uma abordagem da história da energia nuclear para a formação de professores de física. Revista Brasileira de História da Ciência, v. 7, n. 2, p. 232-241, 2014.

.; TADEU NETO. Kleber. Licenciandos em Física e a História e Filosofia da Ciência enquanto abordagem didático-pedagógica. 
In: SIMPÓSIO NACIONAL DE ENSINO DE FÍSICA - SNEF, 21., 26-30 jan. 2015, Uberlândia. Anais eletrônicos... Uberlândia: UFU, 2015. Disponível em: <http://www.sbf1.sbfisica.org.br/eventos/ snef/xxi/sys/resumos/T0557-1.pdf/>. Acesso em: 5 jul. 2016.

YOUTUBE Modern Marvels - Manhattan Project (episode 21, season 9), 2002. Disponível em: <https://www.youtube.com/ watch?v=8kFr5zTxsUM>. Acesso em: 03 out. 2016.

YOUTUBE Maravilhas Modernas Projeto Manhattan Parte 1 File2HD com. 2011a. 1 post (9 min 33 s). Postado em: 15 jun 2011. Disponível em: <https://www.youtube.com/watch?v=OvqdeYcGs O8\&list=PL501D421C1E823A43>. Acesso em :15 jan. 2016.

YOUTUBE Maravilhas Modernas Projeto Manhattan Parte 2. 2011b. 1 post. ( 8 min 39 s). Postado em: 15 jun 2011. Disponível em: <https://www.youtube.com/watch?v=rQHeEE_8gbw\&list= PL501D421C1E823A43\&index=3>. Acesso em: 15 jan. 2016.

YOUTUBE Maravilhas Modernas Projeto Manhattan Parte 3b File2HD com. 2011c. 1 post (9 min. 11 s). Postado em: 15 jun 2011. Disponível em: <https://www.youtube.com/watch?v=okz QS8c6bBA\&index=4\&list=PL501D421C1E823A43>. Acesso em: 15 jan. 2016.

YOUTUBE Maravilhas Modernas Projeto Manhattan Parte 4 File2HD com. 2011d. 1 post (8 min. 52 s). Postado em: 15 jun 2011. Disponível em: <https://www.youtube.com/watch?v=0IHHPKIYpQ\&list=PL501D421C1E823A43\&index=5>. Acesso em: 15 jan. 2016. 